\title{
BENIGN OBSTRUCTION OF THE SUPERIOR VENA CAVA
}

\author{
By A. W. FAwCETT, M.B., F.R.C.S. \\ and B. S. Dhillon, M.B., F.R.C.S.(Eng.), F.R.C.S.(Ed.) \\ Royal Infirmary, Sheffield
}

Hunter ${ }^{1}$ was the first to report a case of superior vena cava obstruction. Ehlrich ${ }^{2}$ et al. and McIntire and Sykes $^{3}$ have extensively reviewed the world literature.

Obstruction of the superior vena cava due to primary endothoracic malignant tumours or aneurysm is not uncommon, accounting for 94 per cent. of our cases, but benign lesions causing obstruction of this vessel are rare. Oschner and Dixon $^{4}$ collected 120 cases of thrombosis of the superior vena cava from the world literature. From the available data they concluded that 44 were due to phlebitis, 35 from external compression, 28 resulted from mediastinitis and in 13 cases the cause was either unstated or unknown. Of the 44 cases of phlebitis and associated thrombosis, only to could be termed as idiopathic. In the remaining the underlying aetiological agent named in order of frequency was syphilis, cardiac disease, pyogenic infections, tuberculosis and trauma. Thrombo-phlebitis arising in the main veins of the upper extremities may spread to involve the superior vena cava. Obstruction of the superior vena cava due to chronic mediastinitis was described by Hallet ${ }^{5}$ and of the 28 cases in the Oschner and Dixon ${ }^{4}$ series I I were due to syphilis, Io to tuberculosis, one to pyaeogenic infection, one to trauma and five to unknown aetiology. Erganin and Wade ${ }^{6}$ reported three cases due to non-specific chronic fibrosing mediastinitis and Tubbs ${ }^{7}$ reported three cases due to chronic mediastinitis; in two of his cases the underlying cause could not be discovered. Benign tumours seldom cause superior vena cava obstruction. McArt et al. ${ }^{8}$ have reported a case of superior vena cava syndrome produced by retrosternal goitre, while McIntire and Sykes ${ }^{3}$ could find only two cases of benign tumours in the world literature. Pericardial bands and adhesions have also been mentioned as sole cause of superior vena cava obstruction. Gray and Skinner ${ }^{9}$ have reported two cases of thrombosis

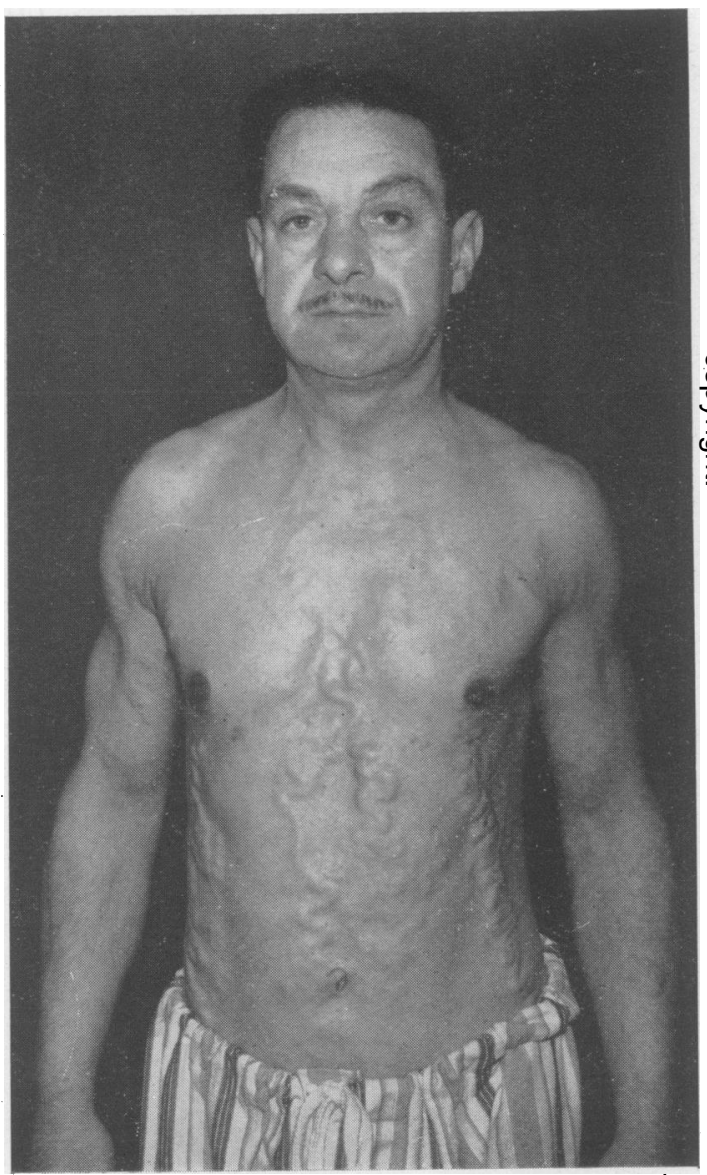

FIG. I.

of the superior vena cava associated with constricting bands.

We are presenting three patients with benign obstruction of the superior vena cava. 


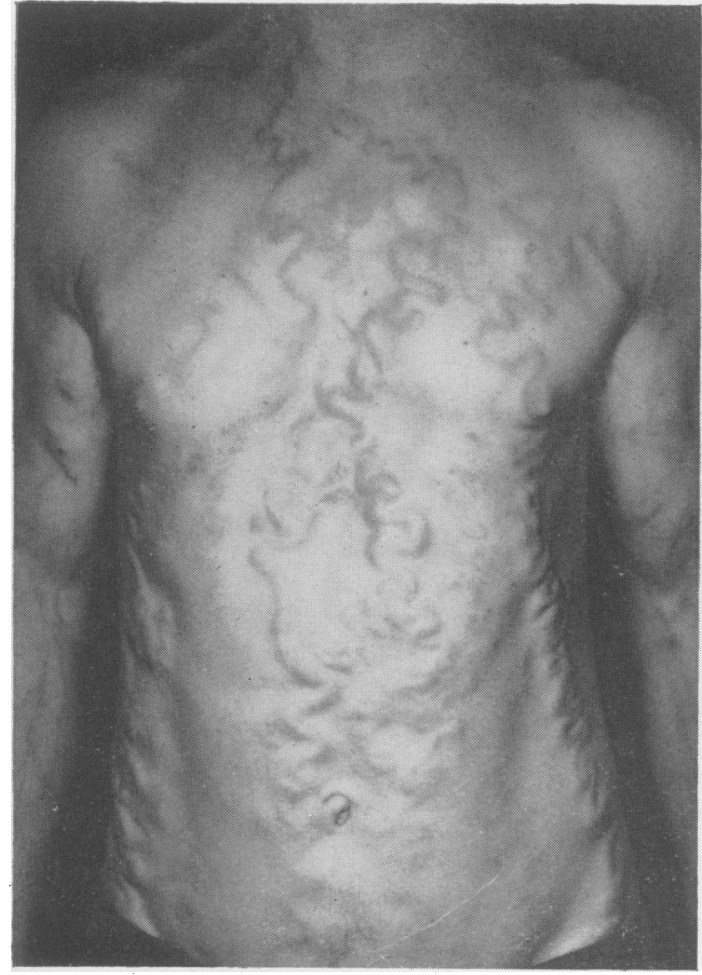

FIG. IB.

\section{Case I}

A male patient aged 49 years was admitted to hospital on March I, 1956, with progressive dyspnoea on exertion and pain in the left chest for four months prior to admission.

\section{Past History}

In 1936 he noticed sudden onset of swelling of both upper limbs, face and neck. He was distressed by intense headaches, dizziness, tinnitus and shortness of breath on slight exertion. He was admitted to a hospital as an emergency with the presumptive diagnosis of Hodgkins' disease involving the mediastinal glands. He was given a short course of D.X.R. therapy to the superior mediastinum, without immediate relief. His general condition improved gradually, but the swelling of his upper limbs, head and neck persisted. Over a period of the next few years tremendously dilated tortuous veins appeared over the front of his chest and abdomen. His headaches, tinnitus and dizziness became less troublesome, but he developed slight deafness. He obtained a job as a surface worker in a coalmine, doing light work, as heavy physical exertion made him unduly short of breath with increased swelling of the face and neck.

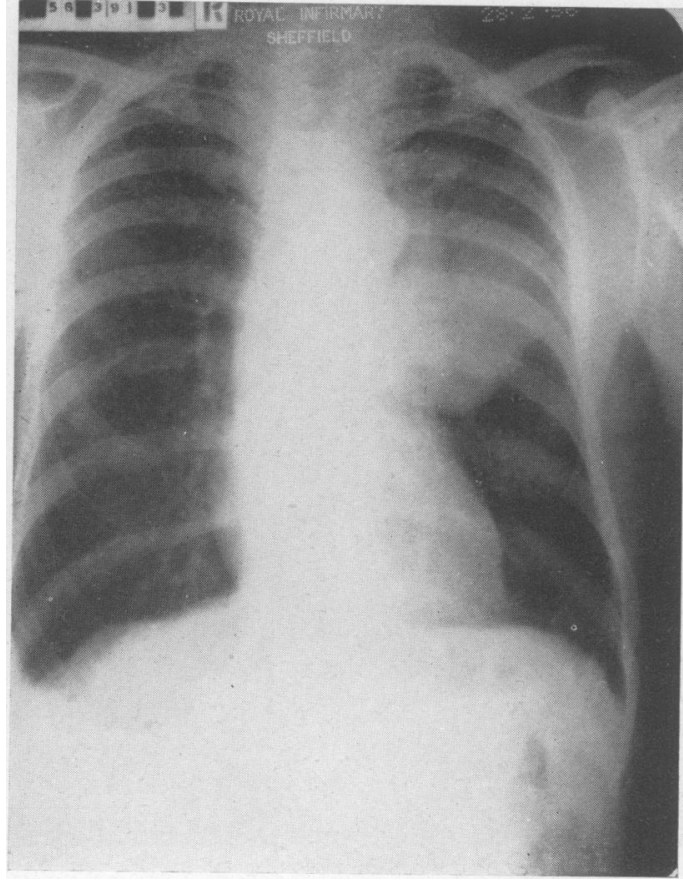

FIG. 2.

Physical examination showed that the upper extremities shared the cyanotic hue of the head and neck, and in contrast the lower extremities were of normal colour. There was swelling of the face and neck, and to some extent of both upper limbs. The eyes were prominent and the eyelids were puffy (Fig. I). The superficial veins in the neck, forehead, both arms and antecubital fossae were distended and prominent. There were tremendously enlarged, tortuous and prominent veins on the anterior aspect of his chest and abdomen and the flow in these was from above downwards. A continuous venous ' hum' was audible over the distended veins on ausculation.

Heart N.A.D. B.P. $120 / 80$.

Lungs: There was dullness on percussion over the apical segment of the left lower lobe with absent breath sounds.

$\mathrm{X}$-ray chest showed a mass occupying the apical segment of the left lower lobe (Fig. 2).

The mediastinum was not widened.

Both diaphragms were mobile. Angiocardiogram showed complete obliteration of the subclavian and innominate veins and the superior vena cava (Fig. 3).

\section{Laboratory Findings}

I. Hb. 80 per cent.

2. W.R. and Kahn negative. 


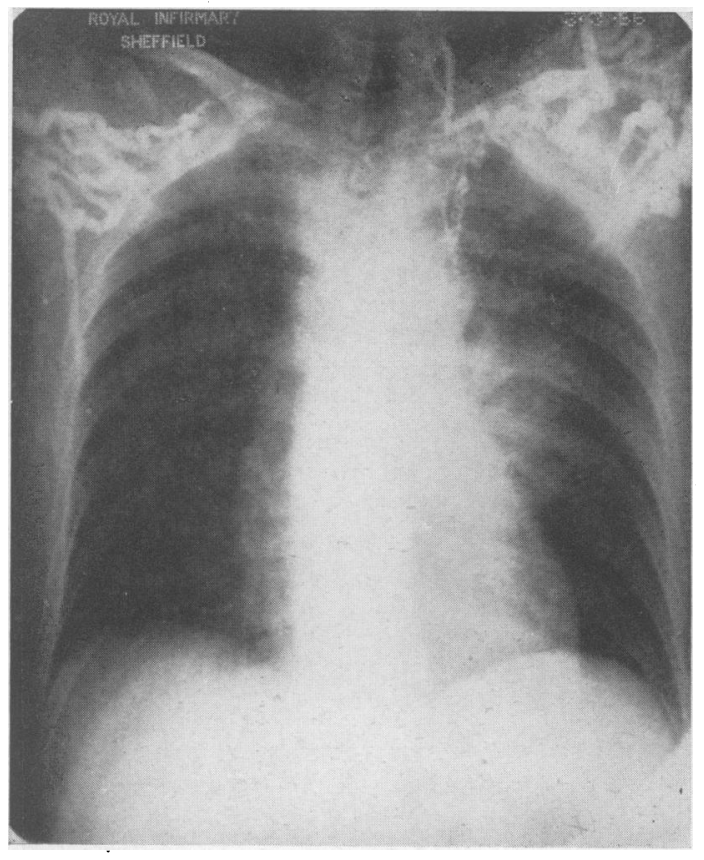

FIG. 3.

3. Vital capacity 2.2 litres.

4. Circulation time (Decholin), arm to tongue, 60 seconds.

\section{Venous Pressures}

Upper limb, antecubital fossa.

$400 \mathrm{~mm}$. of $\mathrm{H}_{2} \mathrm{O}$ above the sternal angle.

The pressure increased to $435 \mathrm{~mm}$. of $\mathrm{H}_{2} \mathrm{O}$ after exercise of the hand and forearm and to $470 \mathrm{~mm}$. of $\mathrm{H}_{2} \mathrm{O}$ after tying a tourniquet around the chest. On deep inspiration the pressure rose to $4 \mathrm{I} 2 \mathrm{~mm}$. of $\mathrm{H}_{2} \mathrm{O}$.

The venous pressure in the lower extremities was $155 \mathrm{~mm}$. of $\mathrm{H}_{2} \mathrm{O}$ and it fell to $153 \mathrm{~mm}$. of $\mathrm{H}_{2} \mathrm{O}$ after exercise of the leg. On deep inspiration the pressure rose to ${ }_{1} 6_{5} \mathrm{~mm}$. of $\mathrm{H}_{2} \mathrm{O}$.

Bronchoscopy showed the mouth of the apical segment of the left lower lobe to be distorted and narrowed, presumably by a growth. From his history and investigations it was concluded that the patient had superior vena cava obstruction for the past 20 years and his recent illness was due to carcinoma of the left lower lobe.

Left pneumonectomy (B.S.D.) was performed on March 29, 1956. At operation it was noticed that he had enlarged intercostal veins. The internal mammary vein was not enlarged. The mediastinum was soft and mobile. The left innominate vein was thickened and its lumen was completely obliterated, presumably by organized

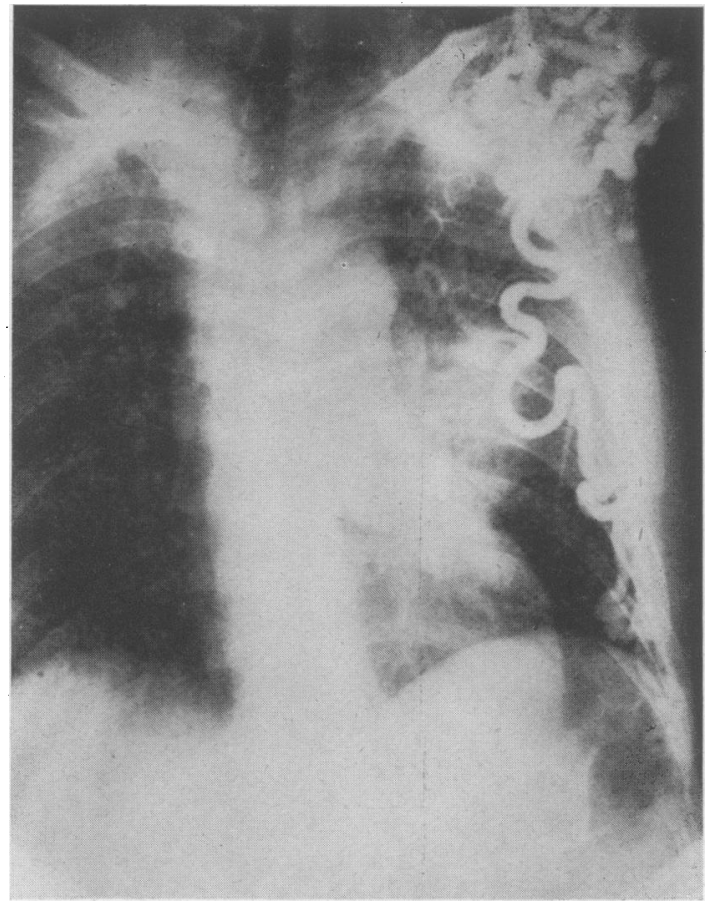

FIG. 4.

thrombus. No lymph glands were seen or palpated in the superior mediastinum.

\section{Case 2}

A female patient aged : 34 was admitted to hospital complaining of swelling of the face and neck, breathlessness on exertion, tinnitus, severe 'bursting' headaches and ' spots' before the eyes. She was perfectly well until I 948 , when she noticed progressive breathlessness and swelling of the face and neck, worse after exertion. She was unable to do her housework, as the slightest exertion and stooping produced violent bursting headaches. She also noticed prominent veins on the front of her chest and around the shoulders.

She was admitted to a hospital in 1950 , when superior vena cava obstruction was diagnosed, and moderate dosage of D.X.R. therapy to the superior mediastinum was given, but the treatment produced no improvement and was discontinued. She became pregnant in $195 \mathrm{I}$ and went through the pregnancy, although at one stage termination of pregnancy was considered because of marked deterioration in her condition. Her dyspnoea and incapacitating headaches persisted and she was referred to us in November 1954 .

\section{Physical Examination}

An obese woman who had swelling of the neck, 


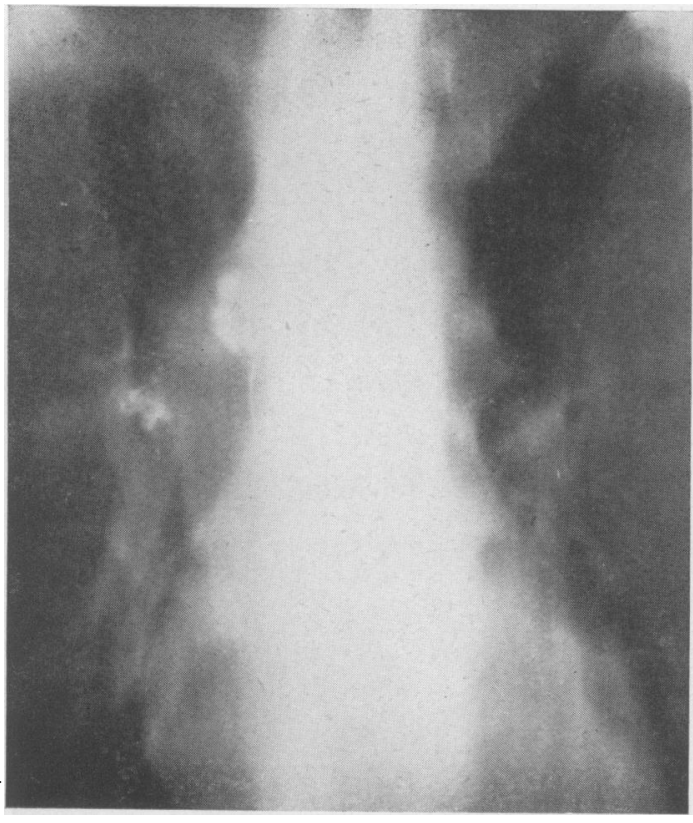

FIG. 5.

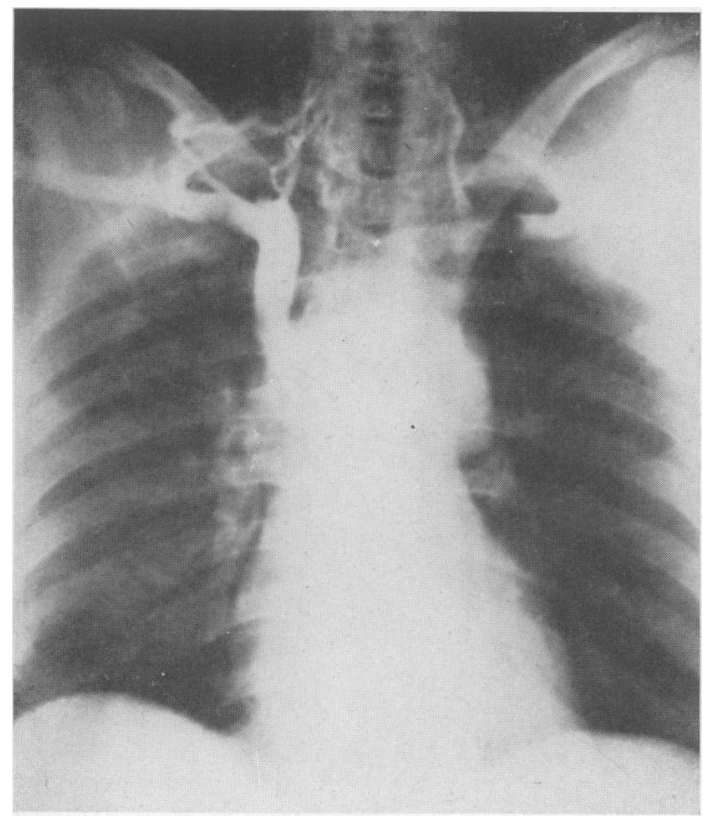

FIG. 6.

face and upper limbs, with cyanotic lips. The superficial veins in the neck, on the anterior aspect of the chest and abdomen were distended and blood flow was from above downwards. The eye-

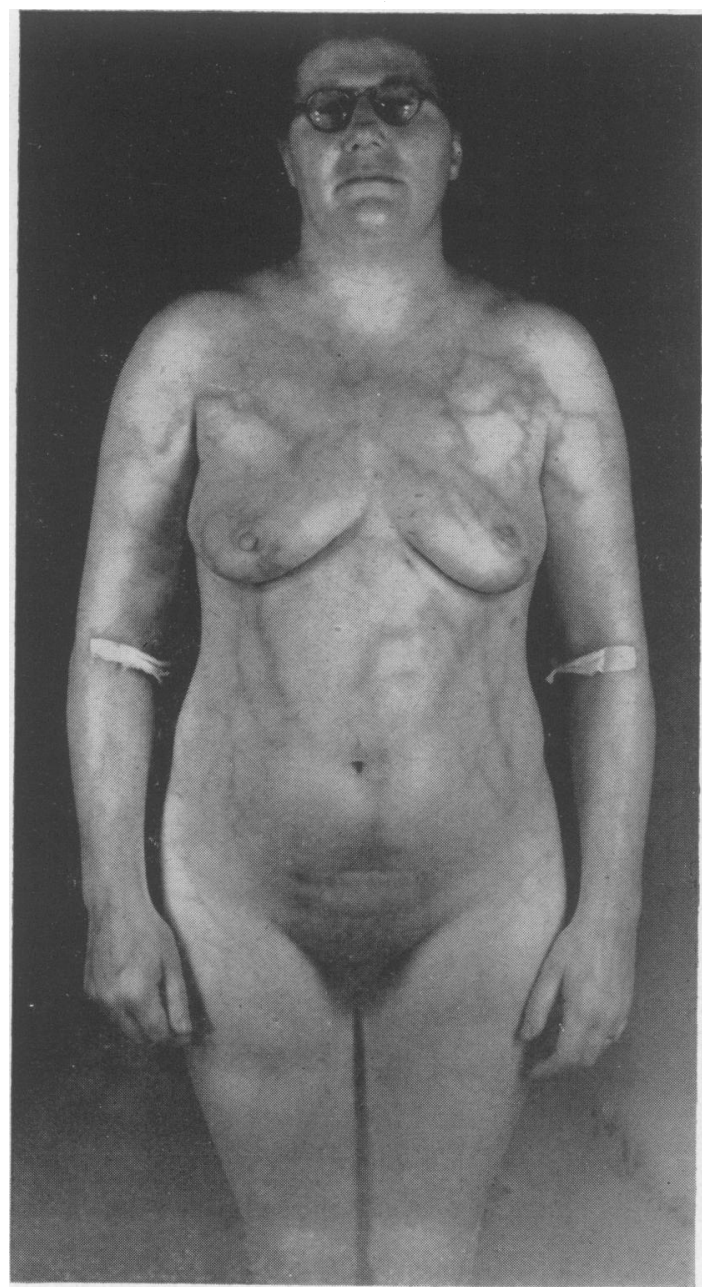

FIG. 7 .

lids were puffy and the retinal veins were prominent and tortuous.

Lungs N.A.D. Heart N.A.D. B.P. $145 / 80$.

$\mathrm{X}$-ray chest showed slight broadening of the superior mediastinum to the right and a group of calcified glands in the right paratracheal area. There was a healed tuberculous focus in the apex of the right upper lobe.

Fluoroscopy: Right diaphragm was paralysed.

Tomograms showed a calcified mass in the right paratracheal area (Fig. 5).

Angiocardiogram showed complete obliteration of the superior vena cava immediately after its commencement (Fig. 6).

Infra-red photograph (Fig. 7) showed widemeshed, abundant subcutaneous veins.

Bronchoscopy revealed no abnormality. 


\section{Laboratory Findings}

I. Hb. $14.5 \mathrm{~g} . / 100 \mathrm{ml}$.

2. R.B.C. $4 \mathrm{I} 9 \mathrm{~m} . / \mathrm{cu} . \mathrm{mm}$.

3. W.B.C. $9,000 / \mathrm{cu} . \mathrm{mm}$.

4. Platelets $200,000 / \mathrm{cu}$. mm. (Lempert).

5. W.R. and Kahn negative.

Bone marrow smear normal.

\section{Direct Venous Pressure Measurements}

I950 (antecubital vein, upper limb): $26 \mathrm{~cm}$. of saline above sternal angle.

$3 \mathrm{I} \mathrm{cm}$. of saline after exercising the hand.

November 6, 1954 (before operation) (antecubital vein, upper limb):

$32 \mathrm{~cm}$. of saline above the sternal angle.

$36 \mathrm{~cm}$. of saline after exercising the hand.

$38 \mathrm{~cm}$. of saline after tying a tourniquet around the costal margin.

$33 \mathrm{~cm}$. of saline on deep inspiration.

Lower Limb ( $4 \mathrm{~cm}$. of saline).

On November 30, 1954, reconstruction of the superior vena cava was carried out with an autogenous venous graft obtained from the right external iliac vein.

\section{Operation (A.W.F.)}

The patient was first placed in the Trendelenburg position and the abdomen opened through the right paramedian incision. The right external iliac vein was isolated and $6 \mathrm{~cm}$. of the vein was removed. The patient was then placed in the left lateral position and the right chest cavity entered through the bed of the resected fourth rib. The superior vena cava, immediately after its commencement, disappeared into a large calcified glandular mass which extended up to the pericardium. The terminal part of the vena azygos was also involved in the mass. The right superior intercostal internal mammary and pericardiophrenic veins were tremendously enlarged and distended. The commencement of the superior vena cava was mobilized and controlled with a Criles clamp. The azygos vein was ligated and divided. The hard calcified mass was dissected off the oesophagus, trachea and aorta up to the pericardium. The pericardium was opened, the intrapericardial part of the superior vena cava was controlled by an auricle clamp and the calcified mass was resected. The vein graft was reversed, the lower end was anastomosed first, followed by the upper end, using interrupted everting sutures with $5 / 0$ arterial silk. After removal of the clamps the graft was functioning well and the chest was closed.

The resected specimen (Fig. 8) consisted of an irregular hard nodule $3.75 \mathrm{~cm}$. in maximum diameter which was extensively calcified. A large

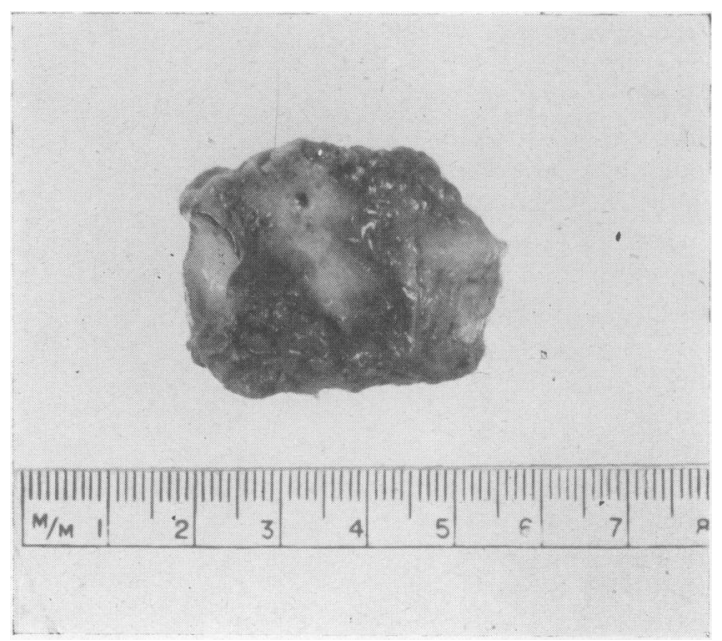

FIG. 8.

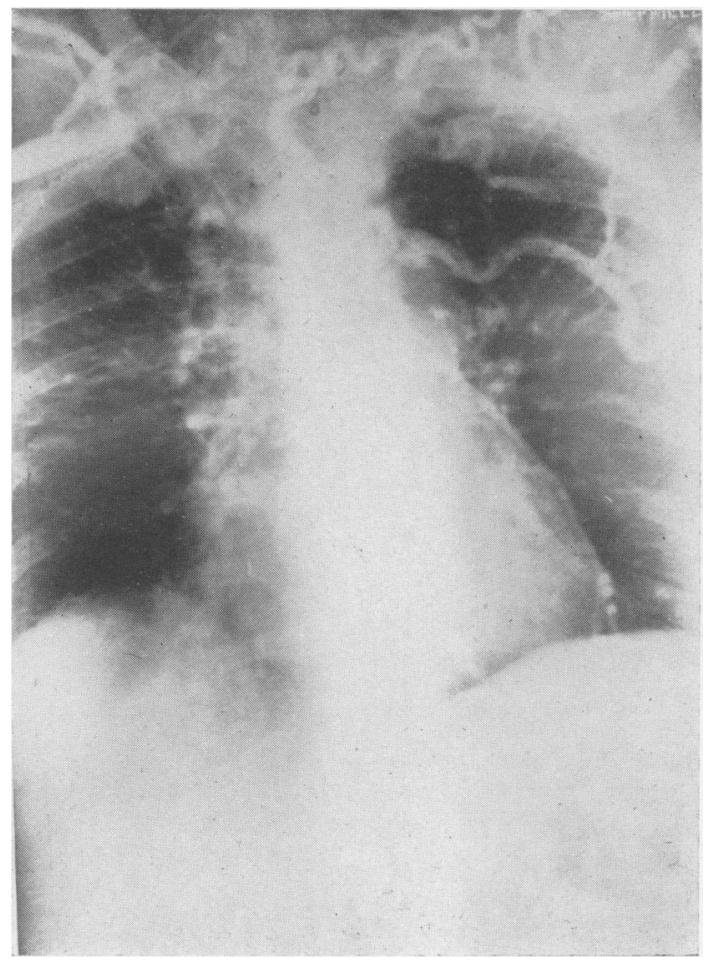

FIG. 9.

vein $1.2 \mathrm{~cm}$. in diameter entered one end of the specimen and a part of it could be identified at the other end. Cross-section of the specimen showed a solid calcified fibrous mass with no apparent lumen. 


\section{Histology}

' The vessel is occluded by abundant collagenous fibrous tissue containing well-formed bone with adipose marrow and many deposits of granular calcium. A few small endothelial-lined channels lie in the centre of the mass.'

Her immediate post-operative progress was smooth. The swelling of the face and neck almost disappeared.

Venous pressures in the upper limb on December 2, 1954, were $20 \mathrm{~cm}$. of saline and it rose to $2 \mathrm{I}$ $\mathrm{cm}$. after exercise of the hand. About four weeks after the operation it was noticed that the eyelids were ' puffy,' the neck veins were distended and there was obvious swelling of the neck and face. Angiocardiogram on December 29, 1954, showed that the graft had thrombosed and thrombosis had extended to involve the innominate and subclavian veins (Fig. 9).

She was last seen in the follow-up clinic on May 10, 1956, when it was noticed that tremendously enlarged and tortuous veins had appeared in front of her chest and abdomen. With the establishment of this abundant collateral circulation the swelling of the face and neck had diminished, the headaches were less troublesome and she could manage light housework.

Venous pressure in the upper limbs on May 10, 1956, were:

$30 \mathrm{~cm}$. of saline above the sternal angle.

$34 \mathrm{~cm}$. of saline after exercise of the hand.

$4 \mathrm{I} \mathrm{cm}$. of saline after tying a tourniquet around the costal margin.

$32 \mathrm{~cm}$. of saline on deep inspiration.

Left lower limb $14 \mathrm{~cm}$. of saline.

\section{Case 3}

A woman aged 57 years was admitted to hospital on August I, 1954, complaining of swelling of the face and neck, headache, slight breathlessness on exertion and a bursting sensation in the head associated with dizziness on bending down. In early $195^{\circ}$ she noticed intermittent swelling of the face and neck, which was worse on stooping and after physical exertion. She had to sleep propped up to avoid dizziness. About six months prior to her admission she noticed prominent veins on the front of her chest.

\section{Past History}

She had pleurisy in 1928 following the birth of her first child. In 1932 she had a mass of tuberculous lymph glands excised from the left cervical region.

\section{Physical Examination}

An obese woman with swelling of the face, neck and upper limbs and slight cyanosis of the lips.

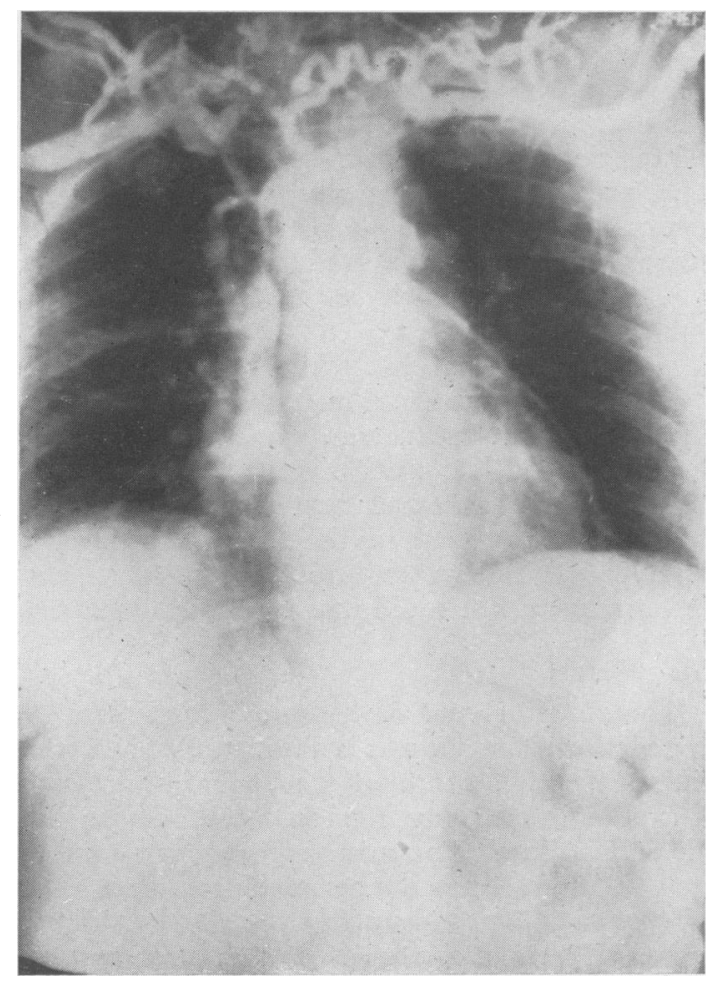

Fig. 10.

The superficial veins in the neck were grossly distended and those of the upper extremities slightly so. The subcutaneous veins on the front of the chest and along the costal margin were prominent and dilated, but no veins were seen crossing the costal margin.

Heart N.A.D. B.P. 145/75. Lungs N.A.D.

Radiograph of chest: Lungs normal, heart normal, superior mediastinum not widened.

Tomograms of the superior mediastinum showed indentation of the right border of the trachea just above the carina, presumably due to the enlarged glands.

Angiocardiogram showed localized incomplete obstruction of the superior vena cava and right innominate vein (Fig. 10).

Bronchoscopy showed marked congestion of the larynx and narrowing of the trachea just above the carina. Only a limited view could be obtained on account of the free bleeding from the congested mucous membrane of the trachea. Aspiration biopsy was negative for malignant cells.

\section{Direct Venous Pressure Measurements}

(Antecubital vein of the upper limbs.)

Right arm: $+26 \mathrm{~cm}$. of saline (above the sternal angle). 
Left arm: $+28 \mathrm{~cm}$. of saline.

The pressure rose to $32 \mathrm{~cm}$. of saline after exercise of the hand and to $29 \mathrm{~cm}$. of saline after tying a tourniquet around the costal margin.

Free fluctuations were noticed with respiration. The pressure decreased by $1.5 \mathrm{~cm}$. on deep inspiration. The venous pressure in the lower limbs was $13.5 \mathrm{~cm}$. of saline.

\section{Laboratory Findings}

1. Hb. $12.5 \mathrm{~g} . / 100 \mathrm{ml}$.

2. R.B.C. $4.3 \mathrm{~m} . / \mathrm{cu} . \mathrm{mm}$.

3. W.B.C. $4,000 / \mathrm{cu} . \mathrm{mm}$.

4. W.R. and Kahn negative.

5. Bone marrow smear non-specific.

She was last seen in the follow-up clinic in March 1956. She was still troubled with headaches and dizziness, but could manage light housework.

\section{Discussion}

The superior vena cava drains blood from the upper half of the body, it is a thin-walled structure and the blood flow through it is under low pressure. It is about $7 \mathrm{~cm}$. long, the last $2 \mathrm{~cm}$. being within the pericardium. The vena azygos joins it immediately before it enters the pericardium. As a result of occlusion of the superior vena cava there is increased venous pressure in the corresponding half of the body and the degree of venous hypertension depends on the obstruction being complete or partial, and also on the location of the block with reference to the opening of the azygos vein. Fischer ${ }^{10}$ has divided the obstruction into three anatomical types:

I. Obstruction below the orifice of the azygos vein.

2. Obstruction including the azygos vein.

3. Obstruction above the azygos vein.

Carlson ${ }^{11}$ demonstrated in dogs that venous pressure rapidly returns to normal if the obstruction was above the vena azygos opening, but with occlusion of both the vena cava and the azygos vein the high venous pressure was maintained for long periods.

After occlusion of the superior vena cava there is an attempt to develop collateral circulation and on the efficiency of the collateral circulation depends the degree of invalidism. There are two routes available: I. Superficial collateral circulation. 2. Deep collateral circulation.

The superficial system comprises the vein on the front of the chest and abdomen, the lateral thoracic and superficial epigastric veins. The deep system consists of the internal mammary, the vertebral and the azygos system. The level of obstruction with reference to the azygos opening will determine which routes will predominate in the collateral flow. If the obstruction is situated above the azygos opening, the direction of the blood flow is normal, i.e. towards the superior vena cava via the azygos system; if the opening of the vena azygos is also occluded, the blood has to return to the inferior vena cava to reach the heart, and it does so via the superficial, the internal mammary and the vertebral system, but once the thrombosis has extended to involve the innominate veins the internal mammary plays a very minor part in the collateral circulation. This was well illustrated in two of our cases (Case I, W., and Case 2, P.). In Case I the innominate veins were also thrombosed and at left thoracotomy it was noticed that the internal mammary vein was of normal size, but in Case 2 the innominate veins were patent and at the time of reconstruction of the superior vena cava it was noticed that the internal mammary vein was tremendously enlarged.

The site of block with reference to the azygos opening can be localized from the distribution of the superficial collaterals; if the venous collaterals are seen crossing the costal margin, it is fairly certain that azygos opening is included in the block (Fig. I).

The degree of signs and symptoms is dependent on the rapidity of the occlusion. In the acute stage there is engorgement of the veins followed by rapid development of oedema in the area drained by the superior vena cava.

The oedema of the face, neck and upper extremities may be intermittent first, exaggerated by exercise, bending forward and recumbent position. The eyelids are usually ' puffy' and the eyes may be prominent. Oedema of the mucous membranes of the mouth, pharynx, larynx and trachea may also occur. Rauth ${ }^{12}$ states that oedema of the glottis may cause sudden death. One of our patients (Case 3 ) had marked oedema of the larynx and trachea. The conjunctiva may be suffused and fundoscopic examination may show prominence and tortuosity of the retinal veins. Oedema of the upper half of the body is in part result of venous hypertension, providing increased filtration pressure, and in part due to anoxia secondary to stasis.

Cyanosis of the upper limbs, face, neck, and especially of the lips and lobes of the ears, is a prominent feature, which is due to translucency of tremendously over-distended subcutaneous veins and is accentuated by abnormal deoxygenation of capillary blood due to stasis.

Dyspnoea is a prominent and early complaint and it can be incapacitating till an efficient collateral circulation is established. According to Veal and Costonas, ${ }^{13}$ dyspnoea is primarily due to underlying disease of the lung. Two of our patients (Case 2 and Case 3 ) had no underlying lung pathology and the third patient (Case I) had dyspnoea for 20 years, though it was recently 
aggravated by carcinoma of the left lung. Studies of the arterio-venous oxygen difference indicate stasis in the tissues drained by the superior vena cava. ${ }^{14}$

There is increase in the spinal fluid pressure as demonstrated by Ferris. ${ }^{15}$ Stasis in the brain associated with raised intracranial pressure, which itself slows down brain circulation, may cause dyspnoea. Headache may be a presenting symptom and other symptoms, such as tinnitis, deafness, dizziness, vertigo, syncope, convulsions, epistaxis and hoarseness, have been reported.

The above clinical findings in the presence of elevated venous pressure in the upper extremities and normal venous pressure in the lower extremities is sufficient to make diagnosis of the superior vena cava syndrome. The normal venous pressure, in the upper extremities, varies between 50 to $150 \mathrm{~mm}$. of saline (with reference to the sternal angle) and the column of saline shows slight fluctuations with respiration-a small fall on inspiration due to increase in the intrathoracic negative pressure and slight rise on expiration. When the superior vena cava is blocked and the mouth of the azygos vein is included in it (Case I and Case 2) there is not only increase in the venous pressure in the upper limbs, but there is also paradoxical fluctuations ${ }^{16}$ of the column of saline in the manometer (i.e. rise with inspiration and fall with expiration). The venous pressure in the lower limbs is not elevated and normally the column of saline rises on inspiration and falls with expiration.

In normal individuals there is no rise in venous pressure after exercise, but if a patient with superior vena cava syndrome is asked to exercise his hand it will produce sharp increase in the venous pressures (Cases 1,2 and 3 ). The elevation of venous pressure on exercise is quite characteristic in this syndrome.

There is also rise in the venous pressure if the superficial collateral circulation is obstructed by tying a tourniquet around the costal margin (Case $I$ and Case 2).

\section{Circulation Time}

The arm to tongue circulation time (Decholine) was prolonged in two patients (Case I, 60 seconds; Case 2, 40 seconds) who had complete obliteration of the superior vena cava, including the azygos opening. This is not surprising, as the blood from the upper half of the body has to take circuitous route to reach the heart, though we are aware of the conflicting reports by other observers. ${ }^{16}, 17,18$

\section{Phlebography}

'Simultaneous bilateral injection technique.' About 15 c.c. of 75 per cent. diodon is injected simultaneously into medial cubital veins of both arms and nine films are exposed over a period of I 5 seconds, demonstrating the site and degree of obstruction and the collateral circulation. I This also helps to outline the reconstructive problem with great accuracy. In Case I we thought that all the dye was being diverted through the superficial circulation without reaching the deep circulation (Fig. 3); we attempted to outline the subclavian and the innominate veins by selective phlebography. A cardiac catheter was passed through the medial cubital vein, but progress of the catheter was completely arrested before it entered the subclavian vein (Fig. 4), indicating that superior vena cava, the innominate and the subclavian veins were thrombosed.

\section{Prognosis}

The slow occlusion of the superior vena cava is compatible with long life. The prognosis depends partly on the rapidity of occlusion-with a slow sclerotic process (Cases 1,2 and 3 ) there is sufficient time for adequate collateral circulation to be established-and also on the nature of the occluding process. If the aetiological agent is primary or secondary malignant endothoracic tumour, the prognosis is hopeless.

\section{Treatment}

Graham et al..$^{2}$ have reported marked improvement in a patient with mediastinal decompression. Tubbs? reached the conclusion that it is an unjustifiable procedure which produces no benefit to the patient. Gray and Skinner ${ }^{9}$ have reported beneficial effects following the divisions of the constricting bands. Klassen et al. $^{20}$ anastomosed the azygos vein to superior vena cava and Samson ${ }^{21}$ has reported a case of venous autograft between the right innominate vein and the superior vena cava. The replacement of major veins by venous autograft is, on the whole, disappointing. In our patient (Case 2), in spite of the graft being of adequate length, size and functioning well at the time of operation, it. was completely thrombosed within the first few weeks after operation. Holman and Steinberg ${ }^{22}$ used an aortic homograft; the graft stayed functioning for the first Io months, but, according to Glenn et al., ${ }^{23}$ it has now thrombosed with elevation of venous pressure in the upper limbs. Deterling and Bhonslay ${ }^{24}$, after experimental studies in dogs, have reported their preference for aortic homografts, while venous autografts and synthetic tube grafts give disappointing results.

The best method of restoring the continuity of blood vessels is by an end-to-end anastomosis. Gerhode ${ }^{25}$ and his associates have suggested to bypass the superior vena caval obstruction by 
anastomosing the distal end of the superior vena cava to the auricular appendage. We explored the possibility on several cadavers and several hearts obtained from the post-mortem room. The size and shape of the right auricular appendage is extremely variable and a definite increase in length can be obtained by gentle dissection in the groove between the auricular appendage and the auricle (varying between 0.5 and $1.5 \mathrm{~cm}$.). After the mobilization it was possible to anastomose the auricular appendage with the distal part of the superior vena cava and the procedure was greatly facilitated by opening the pericardium freely.

It appears to us that Gerhode has made a very useful suggestion, and this possibility should be explored when reconstructing the superior vena cava.

\section{Conclusion}

I. Benign obstruction of the superior vena cava is compatible with long life, though not necessarily with normal life (Case I).

2. The problem of reconstruction of the superior vena cava has not been satisfactorily solved.

3. It is unjustifiable to embark on reconstruction of the superior vena cava unless the repeated estimation of venous pressures in the upper limbs show progressive increase and is associated with incapacitating symptoms (Case 2).

\section{Summary}

I. The case histories and results of relevant investigations on three patients with benign obstruction of the superior vena cava for the past 20 , eight and six years are reproduced.

2. The cause of obstruction in Case I was spontaneous thrombosis and in Case 2 and Case 3 the obstruction was produced by tuberculous lymph glands.
3. One of these patients (Case 2) had incapacitating symptoms with progressive rise in the venous pressure. The blocked superior vena cava was resected and replaced by an autogenous venous graft.

\section{REFERENCES}

I. HUNTER, W. (1757), Med. Obs. and Inq. (Lond.), I, 323.

2. EHLRICH, W., BALLON, H. C., and GRAHAM, E. A. (1934) f. thorac. Surg., 3, 352 .

3. MCINTIRE, F. G., and SYKES, E. M. (1949), Ann. intern. Med., 30, 925.

4. OSCHNER, A., and DIXON, J. L. (1936), F. thorac. Surg. 5, 641.

5. HALLET, C. H. (1848), Edinb. med. F., 69, 269.

6. ERGANIN, J., and WADE, L. J. (1943), f. thorac. Surg., I2, 275.

7. TUBBS, O. S. (1946), Thorax, r, 247.

8. MCART, B. A., RAMSAY, F. B., and TOSSIK, W. A. (1954), A.M.A. Arch. Surg., 69, I I.

9. GRAY, H. K., and SKINNER, I. C. (I94I), Surg. Gynec. Obst. 72, 923.

10. FISCHER, J. (1904), 'Veber Verengerung und Verschliissung der Vena Cava Superior,' Theses, Halle.

11. CARLSON, H. A. (1934), Arch. Surg., 24, 669.

12. RAUTH (1935), quoted by Graham, E. B., Singer, J. J., and Ballon, H.C., ' Surgical Diseases of Chest.' 13. VEAL, J. R., and COSTONAS, N. J., JUN. (1952), Surgery,
3I, I.

14. ATTSCHULE, M. D., IGLANER, A., and ZAMCHECK, N. (1954), Arch. intern. Med., 75, 24.

15. FERRIS, E. B., JUN. (1939), $\mathfrak{F}$. clin. Invest., 18, 19.

16. HUSSEY, H. H., KATZ, S., and YATER, W. M. (1946), Ann. Heart $\mathcal{F}$., 3I, I.

17. LIAN, C., and ABAZA, A. (1935), Bull. Mem. Soc. Med. Hop Paris, 51, 730 .

18. RENBOURN, E. T. (1946), Thorax, 1, 257.

19. ROBERTS, D. J., JUN., DOTTER, C. T., and STEINBERG I. (1951), Amer. F. Roentgenol., 66, $34 \mathrm{I}$.

20. KLASSEN, K. P., ANDREWS, N. C., and CURTIS, S. M (1951), A.M.A. Arch. Surg., 63, 311 .

21. SAMSON, P. C., in discussion, LELL, W. A. (r95 I), Ann. Otol. (St. Louis), 60, 754 .

22. HOLMAN, C. W., and STEINBERG, I. (1954), F.A.M.A. I55, 1403

23. GLENN, F., KEEFER, E. B. C., and LAZZARNI, A. A (1956), Surg. Clin. N. Amer., Vol. 36, No. 2, 437.

24. DETERLING, R. A., and BHONSLAY (1955), Surgery, 38, 91 .

25. GERHODE, F., YEE, J., and RUNDLE, F. F. (1949), Ibid. 25,556 .

\section{RUTHIN CASTLE, NORTH WALES}

A Clinic for the diagnosis and treatment of Internal Diseases (except Mental or Infectious Diseases). The Clinic is provided with a staff of doctors, technicians and nurses.

The surroundings are beautiful. The climate is mild. There is central heating throughout. The annual rainfall is $\mathbf{3 0 . 5}$ inches, that is, less than the average for England.

The Fees are inclusive and vary according to the room occupied.

For particulars apply to THE SECRET:ARY, Ruthin Castle, North Wales.

Tolezrams: Caods, Ruthin.

Telophene: Ruchin 66 